\title{
¿Justicia social o revictimización de la trabajadora doméstica mexicana? Análisis de la sentencia 9/2018 de la Suprema Corte de Justicia de la Nación
}

\author{
Social Justice or revictimization of the Mexican female \\ domestic worker? Analysis of judgement 9/2018 \\ by Supreme Court of Justice of Nation
}

\author{
Augusto Fernando Carrillo Salgado* \\ Universidad Nacional Autónoma de México \\ ORCID ID: 0000-0001-6107-4917
}

Recibido: $13 / 5 / 2021$

Aceptado: 30/6/2021

doi: https://doi.org/10.20318/labos.2021.6491

\begin{abstract}
Resumen: $\quad$ En este documento se exponen los argumentos principales de la sentencia 9/2018, dictada por la segunda sala de la Suprema Corte de Justicia de la Nación, con el propósito de determinar si tuvo o ha tenido algún impacto positivo real en favor de la impetrante y demás trabajadoras domésticas mexicanas o si, por el contrario, tan solo ha permanecido como una enunciación de buenos deseos que podría, en última instancia, revictimizarlas. Primero se explica, de manera general, el origen y contenido del fallo, después son destacados sus aspectos positivos y negativos, por último, son desarrolladas las conclusiones. Los métodos empleados para la elaboración de esta reflexión jurídico-filosófica son el deductivo, analítico y dialéctico. La postura epistemológica es el positivismo inclusivo.

Palabras clave: trabajadoras domésticas, seguridad social, reforma constitucional de junio de 2011, Suprema Corte de Justicia de la Nación, sentencias dialógicas.

Abstract: $\quad$ This paper presents the main arguments of judgement 9/2018 by Supreme Court of Justice of Nation, with the purpose of determining whether it has had a real and positive impact in favor of the impetrating and Mexican female domestic workers or if, on the contrary, it has only remained as an enunciation of good wishes which could revictimized them. First, the origin and content of the judgements, in general terms, are explained, then its positive and negative aspects are highlighted, and finally, the conclusions are developed. The methods used for the elaboration of this legal-philosophical reflection are deductive, analytical, and dialectical. The epistemological position is inclusive positivism.

Keywords: female domestic workers, social welfare, constitutional reform of June 2011, Supreme Court of Justice of Nation, dialogical judgements.
\end{abstract}

"Estudiante de doctorado en derecho por la Universidad Nacional Autónoma de México (UNAM); licenciado y maestro en derecho, con mención honorífica, por la misma institución; y especialista como secretario de juzgado por la Escuela Judicial del Instituto de la Judicatura Federal (IJF). Agradezco al CONACYT por su apoyo para la redacción de este trabajo.

fernando90@comunidad.unam.mx 


\section{Introducción}

En los primeros meses del año dos mil veintiuno, el Centro de Estudios Constitucionales de la Suprema Corte de Justicia de la Nación (México) organizó un curso en línea, denominado Actualización intensiva en 10 años de jurisprudencia, con motivo del décimo aniversario de la reforma constitucional en materia de derechos humanos (DDHH) de junio de $2011 .{ }^{1} \mathrm{El}$ primero de los módulos llevó por título Igualdad y no discriminación. Como material pedagógico, el Centro de Estudios Constitucionales puso a disposición del público participante un corpus de sentencias dictadas en la última década por la Suprema Corte de Justicia de la Nación, con la finalidad de analizar y comprender la evolución de algunas figuras normativas y jurisprudenciales del derecho mexicano. Entre estas sentencias se encuentra la resolución 9/2018 dictada por la segunda sala de la Suprema Corte de Justicia de la Nación que trata la situación jurídica de las trabajadoras domésticas frente al derecho del trabajo y seguridad social mexicanos.

Sin duda alguna, es necesaria una reflexión crítica en torno a la estructura, contenido y alcances de la sentencia, a pesar de los ańos transcurridos desde que fue dictada. Es, precisamente, el transcurso del tiempo lo que permite dilucidar si los objetivos postulados en ella se han materializado (eficacia de la norma), en qué medida o si, por el contrario, los razonamientos vertidos en esta resolución han permanecido en el reino de las buenas intenciones.

Por lo que respecta al orden expositivo adoptado para la elaboración de la presente reflexión jurídico-filosófica, primero se explica el origen y contenido general de la sentencia, posteriormente, se exponen los aspectos positivos y negativos del fallo 9/2018 de la segunda sala de la Suprema Corte de Justicia de la Nación, por último son desarrolladas las conclusiones de este documento. Los métodos empleados son el deductivo, dialéctico y analítico; la postura epistemológica es el positivismo inclusivo.

\section{Antecedentes y contenido general de la sentencia 9/2018 de la segunda sala de la Suprema Corte de Justicia de la Nación}

\subsection{Sobre el juicio de origen o juicio natural}

La parte actora (cuyo nombre se ignora porque se encuentra testado en la versión pública de la sentencia 9/2018) presentó su demanda laboral ante la Unidad Jurídica de la Oficialía de Partes de la Junta Local de Conciliación y Arbitraje² de la Ciudad de México (CDMX), el día 28 de abril de 2016, en contra de dos personas físicas (cuyos nombres también se desconocen) y llamó como terceros interesados al Instituto Mexicano del Seguro Social e Instituto del Fondo Nacional de la

\footnotetext{
${ }^{1}$ Véase, CRUZ PARCERO, Juan Antonio, Hacia una teoría constitucional de los derechos humanos, México, Instituto de Estudios Constitucionales del Estado de Querétaro, 2017, pp. 39-65; CARRILLO SALGADO, Augusto Fernando, Panorama de la protección de los derechos de las trabajadoras en España y México, Labos. Revista de Derecho del Trabajo y Protección Social, Vol. 1, No. 3, 2020, pp. 60-61. La reforma constitucional en materia de DDHH de junio de 2011, significó un cambio de paradigma en la impartición de justicia en México porque se transitó de un esquema formal, positivista, basado en la subsunción; a un modelo más amplio donde las fuentes del derecho se han enriquecido con los tratados internacionales de DDHH y sentencias de la Corte Interamericana de DDHH. Algunos autores han querido ver en este cambio de paradigma un tránsito del iuspositivismo al iusnaturalismo, lo que es falso. En realidad, el paradigma actual podría denominarse positivismo inclusivo ya que no se niega el carácter jurídico de las normas sino que se admite la necesidad de incluir ciertas consideraciones morales, tanto en las sentencias de las autoridades jurisdiccionales, como en todas las actuaciones del Estado mexicano.

${ }^{2}$ La Junta Local de Conciliación y Arbitraje podría definirse como un tribunal encargado de dirimir las controversias entre patrones y trabajadores integrado por representantes del Estado mexicano (fuero federal o local, según sea el caso), patrones y trabajadores.
} 
Vivienda para los Trabajadores. ${ }^{3}$ La actora prestó sus servicios para las codemandadas como trabajadora doméstica. En su demanda, reclamó el pago de diversas prestaciones, entre ellas: indemnización constitucional, pago de salarios caídos, aguinaldo, vacaciones, prima vacacional, prima de antigüedad, horas extras y, lo más importante, la inscripción retroactiva ante el Instituto Mexicano del Seguro Social e Instituto del Fondo Nacional de la Vivienda para los Trabajadores ${ }^{4}$. La antigüedad de la trabajadora es uno de los elementos más importantes de esta controversia -sobre el particular se volverá más adelante-, en el capítulo de hechos, esclarece la impetrante:

1. La suscrita ingresé a prestar mis servicios en fecha 11 de enero de 1959, al ser contratada por la demandada $* * * * * * * * * * * * * * * * * *$; como patrona, y posteriormente al crecer sus hijas a últimas fechas también como patrona a la demandada ${ }^{* * * * * * * *}$, quienes me contrataron con la categoría de doméstica, y con un salario último de $\$ * * * * * * * * *$, semanales 5 .

Las codemandadas aceptaron la existencia de la relación laboral, pero esgrimieron como defensa la renuncia escrita de la trabajadora. El día 9 de febrero de 2017, la Junta Especial número 19 de la Junta Local de Conciliación y Arbitraje de la CDMX dictó un laudo (sentencia laboral) en donde consideró acreditada la renuncia voluntaria de la trabajadora doméstica, razón por la cual absolvió a las demandadas del pago de la indemnización constitucional y salarios caídos. Sin embargo, estimó no probada la excepción de pago de vacaciones, prima vacacional, aguinaldo y horas extras, por lo que condenó al pago de estas prestaciones, pero solo respecto al ańo anterior a la presentación de la demanda (prescripción negativa en términos del artículo 516 de la Ley Federal del Trabajo ${ }^{6}$ ).

Por cuanto hace a la inscripción retroactiva ante el Instituto Mexicano del Seguro Social, en su laudo, la Junta Especial 19 absolvió a las codemandadas porque "[el] numeral 338, fracción $\mathrm{II}^{7}$, de la Ley Federal del Trabajo [...] descarta que la parte patronal esté obligada a efectuar la inscripción de tales trabajadores al Instituto Mexicano del Seguro Social ${ }^{8 ”}$; no conforme con ello, la Junta Especial 19 agregó: "[...] el artículo 13, fracción II, de la Ley del Seguro Social, [...] dispone que voluntariamente podrán ser sujetos de aseguramiento al régimen obligatorio los trabajadores domésticos", y concluyó que “[...] el patrón no tiene la obligación de hacer la inscripción ante el referido Instituto de dichos empleados ${ }^{10 ”}$. Finalmente, la Junta Especial 19 absolvió al Instituto Mexicano del Seguro Social del pago de todas las prestaciones reclamadas dado que, al ser un organismo público encargado de prestar servicios de seguridad social. no posee el carácter de patrón.

Inconforme con la resolución, la trabajadora doméstica promovió un juicio de amparo directo en contra del laudo dictado por la Junta Especial 19. En efecto, mediante escrito presentado ante la Secretaría Auxiliar de Amparos de la Junta Local de Conciliación y Arbitraje de la CDMX, la actora presentó su demanda de amparo el día 31 de marzo de 2017 al estimar vulnerados los dere-

\footnotetext{
${ }^{3}$ Véase, SCJN 8/2018, p. 8. El texto íntegro de la sentencia puede consultarse en: https://www.scjn.gob.mx/derechos-humanos/ sites/default/files/sentencias-emblematicas/sentencia/2020-01/Sentencia\%20AD\%209-2018\%20PDF.pdf. El Instituto Mexicano del Seguro Social (IMSS) es un organismo que suministra seguridad social a los trabajadores que no laboran para el Estado mexicano, el Instituto del Fondo Nacional de la Vivienda para los Trabajadores (INFONAVIT) es un ente que recibe las cuotas de los patrones y trabajadores para que los empleados puedan adquirir, eventualmente, un hogar.

${ }^{4}$ idem. A decir verdad, la inscripción retroactiva ante el IMSS e INFONAVIT es el punto central de la sentencia 8/2018.

5 ibidem, p. 9 . Énfasis ańadido, los aspectos testados forman parte del documento original. Nótese la antigüedad de la trabajadora doméstica.

${ }^{6}$ Véase, Nueva Ley Federal del Trabajo, México, Gallardo Ediciones, 2020, p. 127. La Ley Federal del Trabajo sería el equivalente al Estatuto de los Trabajadores (Espańa).

${ }^{7}$ Este artículo, hasta el numeral 340, actualmente se encuentra derogado. Véase, ibidem, p. 87.

${ }^{8}$ SCJN, op. cit., p. 10.

${ }^{9}$ idem. Énfasis añadido.

${ }^{10}$ idem.
} 
chos reconocidos a su favor en los artículos 1, 2, 8, 14, 16, 123 apartado A y 133 de la Constitución Política de los Estados Unidos Mexicanos (CPEUM) ${ }^{11}$.

La demanda de amparo fue conocida, en razón de turno y materia, por el décimo sexto Tribunal Colegiado de Circuito ${ }^{12}$ en materia laboral del primer circuito, mismo que la registró con el número de expediente 9/2018 vinculado con el 8/2018, requirió al presidente de la Junta Especial 19 para que remitiera la totalidad de las constancias, rindiera su informe justificado y presentara las cédulas de emplazamiento del Instituto Mexicano del Seguro Social e Instituto del Fondo Nacional de la Vivienda para los Trabajadores (terceros interesados en el juicio de amparo y juicio natural).

El Tribunal Colegiado de Circuito solicitó a la Suprema Corte de Justicia de la Nación que ejerciera su facultad de atracción para conocer del juicio de amparo, por considerar que el asunto podría sentar un precedente de relevancia nacional, lo que hizo la presidencia de la Suprema Corte de Justicia de la Nación el día 14 de febrero de 2018 para, posteriormente, turnar los autos a su segunda sala.

\subsection{Contenido general de la sentencia 9/2018}

Por medio de este fallo la segunda sala de la Suprema Corte de Justicia de la Nación, grosso modo, ha considerado inconstitucional (así como contrario a la dignidad humana y demás DDHH) que los patrones no estén obligados a inscribir a las empleadas domésticas ante el Instituto Mexicano del Seguro Social porque no existe ninguna razón válida para que la ley las excluya del régimen obligatorio de seguridad social ${ }^{13}$. Además, añade, esta medida exclusiva contribuye a marginalizar a la mujer porque el trabajo doméstico ha sido objeto de condiciones generales de trabajo inadecuadas, jornadas extensas, salarios paupérrimos o miserables, etcétera. Por si fuera poco destaca que, de acuerdo con el Instituto Nacional de Geografía y Estadística, 9 de cada 10 personas que realizan labores domésticas son mujeres ${ }^{14}$.

En suma, estas consideraciones provocan que las trabajadoras del hogar se encuentren en una situación de precariedad y olvido social que contribuye a la creación, perpetración y perpetuación de desigualdades laborales, económicas y sociales entre las mujeres y hombres, así como el sostenimiento de estereotipos y prejuicios de género en donde el trabajo doméstico es considerado "carente de valor" o una actividad "inferior" 15 .

De manera esencial, en esta sentencia se resuelve la controversia en "favor" de la trabajadora; en efecto, la segunda sala de la Suprema Corte de Justicia de la Nación estima que el despido no fue acreditado pues advierte una discrepancia entre las declaraciones de los testigos y la supuesta renuncia escrita, pero no solo eso, se "otorga" el amparo para "poner en conocimiento" del Instituto Mexicano del Seguro Social la condición de vulnerabilidad de las trabajadoras domésticas (como si dicha situación no fuera ampliamente conocida, no solo por el Instituto Mexicano del Seguro

\footnotetext{
11 ibidem, p. 5.

${ }^{12}$ Mexico es un Estado federado, por lo tanto, existen tres órdenes de gobierno: municipal, estatal y federal. Así, el poder judicial mexicano comprende, también, ámbitos competenciales de acuerdo con la división de funciones mencionada. Estos ámbitos son: fuero común y federal. El fuero federal se integra por la Suprema Corte de Justicia de la Nación (pleno o salas), tribunales colegiados de circuito, tribunales unitarios de circuito y juzgados de distrito. Cabe destacar la existencia de un Tribunal Electoral del Poder Judicial de la Federación y plenos de circuito. El juicio de amparo, en principio, se promueve ante tribunales federales.

${ }_{13}$ SCJN, op. cit., p. 1. Respecto a la evolución jurisprudencial del concepto de igualdad formal y material, véase, SCJN 1464/2013, p. 19 y ss. El texto íntegro de la sentencia puede consultarse en: https://www.pjecz.gob.mx/derechos-humanos-e-igualdad-de-genero/documentos-de-interes/sentencias-relevantes-sobre-derechos-humanos-e-igualdad-de-genero/suprema-corte-de-justicia-de-la-nacion/documentos-sobre-derechos-humanos/amparo-directo-en-revision-1464-2013/

${ }^{14}$ idem.

${ }^{15}$ idem.
} 
Social sino por toda la sociedad mexicana desde hace décadas); por si fuera poco, se le plantea un plazo "prudente" de 18 meses (cuyo término concluyó el 30 de junio de 2019) para que implemente un "programa piloto" que tenga como principal fin diseñar un régimen especial de seguridad social para las trabajadoras domésticas.

De acuerdo con las "directrices" de la sentencia de la segunda sala de la Corte, el régimen especial de seguridad social para las empleadas domésticas debería comprender los seguros de: 1) riesgos de trabajo, 2) enfermedades, 3) maternidad y guarderías, 4) invalidez y vida y 5) retiro, cesantía en edad avanzada y vejez. La obligatoriedad de este régimen es otra exigencia del programa piloto que debería proponer el Instituto Mexicano del Seguro Social. Por último, en un claro ánimo "protector", la segunda sala de la Suprema Corte de Justicia de la Nación concluye que:

[...] la finalidad de los anteriores lineamientos consiste en que, [...] el IMSS se encuentre en posibilidades de proponer al Congreso de la Unión las adecuaciones legales necesarias para la incorporación formal del nuevo sistema especial de seguridad social para las trabajadoras del hogar, y en ese sentido, en un plazo no mayor a 3 años, se logre obtener la seguridad social, efectiva, robusta y suficiente a la totalidad de las empleadas domésticas en el país ${ }^{16}$.

Es importante destacar dos exigencias de la sentencia 9/2018 de la segunda sala de la Suprema Corte de Justicia de la Nación: 1) que el Instituto Mexicano del Seguro Social proponga al Congreso de la Unión ${ }^{17}$ un programa piloto para materializar la inscripción obligatoria en el régimen obligatorio de seguridad social a las trabajadoras domésticas de México y 2) que este programa garantice el aseguramiento social, efectivo, de todas las empleadas del país en un plazo de tres años. Sin duda alguna, estos reclamos podrían considerarse dos directrices ideales, moralmente positivas, tanto para el Instituto Mexicano del Seguro Social como para el Congreso de la Unión.

Empero, ambos puntos resultan cuestionables, por ahora es suficiente formular -con cierto ánimo retórico- tres preguntas: ¿está facultado, constitucional y legalmente, el Instituto Mexicano del Seguro Social para proponer programas piloto o iniciativas de ley, ante el Congreso de la Unión, de acuerdo con el marco constitucional y normativo mexicano? ¿una iniciativa de ley, cuerpo de normas o sentencia pueden acabar, real y totalmente, con situaciones de hecho? ¿esta sentencia no revictimizará, en realidad, a la trabajadora doméstica impetrante?

\section{Examen particular de la sentencia 9/2018}

\subsection{Aspectos positivos}

Hasta la fecha, la sentencia 9/2018 ha sido considerada, por diferentes sectores de la población mexicana, un fallo de avanzada por múltiples razones, entre las que destacan, por ejemplo, la ruptura con el vetusto esquema formalista de impartición de justicia (subsunción) al incorporar argumentos basados en el análisis de tratados internacionales en materia de DDHH, introducir métodos como la ponderación ${ }^{18}$ y escrutinio estricto pero, sobre todo, debido a que sigue la estructura de los

\footnotetext{
${ }^{16}$ ibidem, p. 3. Énfasis añadido.

${ }^{17}$ Por decirlo de alguna forma, el Congreso de la Unión es el máximo "parlamento" de la República Mexicana que se encuentra compuesto por todas las legislaturas de las entidades federativas.

${ }^{18}$ Cfr., ALEXY, Robert, La fórmula del peso, trad. de BERNAL PULIDO, Carlos, en ALEXY, Robert, Teoría de la argumentación jurídica. La teoría del discurso racional como teoría de la fundamentación jurídica, 2a ed., Madrid, Centro de Estudios Políticos y Constitucionales, trad. de ATIENZA, Manuel y ESPEJO, Isabel, 2014, p. 349 y ss.
} 
fallos pronunciados por la Corte Constitucional de Colombia ${ }^{19}$ (sentencias dialógicas); esto es, suministra directrices a los entes estatales (órganos y organismos) con la finalidad de crear un balance real entre los poderes y, así, disminuir una situación concreta de desigualdad social.

A pesar de lo positivo que podría parecer, prima facie, esta sentencia, tal y como se demostrará más adelante, el fallo pronunciado por la segunda sala de la Suprema Corte de Justicia de la Nación es contradictorio con la naturaleza del juicio de amparo mexicano, principalmente contraviene el principio de relatividad de las sentencias. Ahora corresponde, exponer los aciertos de la sentencia 9/2018.

\section{a) Estructura y "función conductora"}

Las primeras dos características positivas de la sentencia 9/2018 que saltan a la vista, son su estructura y función conductora. Por lo que respecta a la primera característica, podría describirse la sentencia con una palabra: sencillez. En efecto, antaño era bastante común que las sentencias de la Suprema Corte de Justicia de la Nación fueran áridas en su redacción (aún para los propios abogados mexicanos), extensas y se encontraran plagadas por la transcripción de artículos normativos o textos de jurisprudencia. En este caso sucede lo contrario pues, si bien es cierto la Corte incurre en el mismo error, la magnitud es menor. Es decir, no abundan, como antes, las transcripciones de artículos y jurisprudencias.

Cabe destacar que, aunque existe una mejoría en cuanto a su estructura, esta sentencia no alcanza la sencillez, precisión, y calidad argumentativa de los mejores fallos del Tribunal Constitucional de Espańa. En ese sentido, por ejemplo, en las páginas 9, 10 y 11 se transcriben, de manera innecesaria, pasajes completos de algunas constancias del juicio de origen cuando, en realidad, pudo realizarse una narración sencilla sobre el contenido y circunstancias del juicio natural. Este defecto se repite, además, en las páginas 31 a 34 porque se transcriben artículos completos de la ley del Instituto Mexicano del Seguro Social. Por si fuera poco, se usan de manera indiscriminada las negritas, subrayado o itálicas para destacar pasajes importantes del texto.

Sin duda alguna, para lograr que la población tenga un acceso real a la impartición de justicia es necesario que todos los fallos, sobre todo aquellos que provienen de una corte constitucional, se encuentren redactados en términos claros, sencillos, alejados de los tecnicismos del derecho porque no se trata de elaborar un tratado o exposición erudita sobre ciencia jurídica o hacer gala de un vasto conocimiento del derecho, sino cumplir con dos funciones esenciales a todo Estado social de derecho moderno: la impartición de justicia y la creación de un recurso sencillo y eficaz en favor de los justiciables ${ }^{20}$.

En efecto, esta deuda jurídica, y moral ${ }^{21}$, es más profunda hacia la clase trabajadora de cualquier país, máxime en las naciones latinoamericanas, ya que en no pocas ocasiones los obreros carecen de estudios suficientes como para adentrarse en las discusiones más técnicas del derecho (las cuales, a veces, ni siquiera son comprendidas en su totalidad por los propios jurisconsultos). Así, los fallos de una corte constitucional deben ser pronunciados tomando en consideración, en todo momento, el público al que se dirigen porque las sentencias entrañan, también, una función didáctica $^{22}$. Esto es, la población debe ser capaz de aprender -y, también, aprehender- el sentido y la forma en que pueden hacer valer sus derechos frente a los juzgados y tribunales de su país.

\footnotetext{
${ }^{19}$ Las sentencias dialógicas de la Corte Constitucional de Colombia son un referente para toda América Latina por su estructura y fondo. En efecto, como su nombre lo indica, estas sentencias establecen un vínculo de comunicación entre los entes estatales. En otras palabras, no solo dirimen la controversia constitucional, sino que sus efectos irradian al resto de la población e instituciones.

${ }^{20}$ Cfr., ATIENZA, Manuel, Curso de argumentación jurídica, Madrid, Trotta, 2013, p. 703 y ss.

${ }^{21}$ Cfr., ATIENZA, Manuel, El derecho como argumentación, Isegoría, 21, 1999, pp. 37-47.

${ }^{22}$ Cfr., ATIENZA, Manuel, Las razones del derecho. Teorías de la argumentación jurídica, México, UNAM-IIJ, 2005, p. 204 y ss.
} 
Por otra parte, la segunda característica de la sentencia es, quizá, una de las herramientas constitucionales más innovadoras para el derecho del trabajo y seguridad social mexicanos pero, también y como más adelante se verá, la que mayor problemas ocasiona. A través de la sentencia 9/2018 de la segunda sala de la Suprema Corte de Justicia de la Nación, se trata de emular la función conductora de los fallos de la Corte Constitucional de Colombia.

Como se sabe, las sentencias de la Corte referida se caracterizan por su naturaleza "dialógica" ya que proporcionan una serie de directrices específicas al Estado colombiano para finiquitar un problema social. En otras palabras, las sentencias de la Corte Constitucional de Colombia no se limitan a dirimir la controversia constitucional en favor de las partes, sino que sus efectos irradian a la esfera pública estatal para evitar que los mismos atropellos hacia la sociedad continúen cometiéndose una y otra vez.

En el caso particular de la sentencia 9/2018 la segunda sala de la Suprema Corte de Justicia de la Nación ha tratado de suministrar una serie de pautas al Estado mexicano para que erradique la discriminación hacia las trabajadoras domésticas (no obligatoriedad para el patrón de inscribirlas en el régimen obligatorio de seguridad social del IMSS) y, así, disminuir la brecha laboral entre hombres y mujeres. Lo cierto es que, esta clase de fallos, no son comunes en la impartición de justicia mexicana.

\section{b) Suplencia de la deficiencia de la queja en favor de la trabajadora}

De acuerdo con el fallo de la Segunda Sala de la Suprema Corte de Justicia de la Nación, la Quejosa, en su demanda de amparo directo, tan solo impugna la constitucionalidad de los artículos 146 y 338 de la Ley Federal del Trabajo por considerar que establecen una distinción injustificada (discriminatoria) al no contemplar el servicio doméstico como parte del régimen obligatorio ante el Instituto Mexicano del Seguro Social.

Sin embargo, a consideración de la Sala, el reclamo de la Quejosa va mucho más allá pues, en realidad, el problema constitucional de fondo no solo debe abarcar los numerales 146 y 338 de la Ley Federal del Trabajo, sino todas aquellas disposiciones que obstaculicen la inscripción de las trabajadoras domésticas ante el régimen obligatorio ante el Instituto Mexicano del Seguro Social ${ }^{23}$, de ahí que la Sala centre su atención no solo en las normas de la Ley Federal del Trabajo impugnadas, sino también sobre aquellas de la ley del Instituto Mexicano del Seguro Social, en particular el artículo 13, fracción II.

\section{c) Análisis exhaustivo del contenido y alcance del principio de igualdad y condición de la trabajadora doméstica en México}

Como se sabe, el caso entraña una diferenciación discriminatoria hacia las trabajadoras domésticas. Para determinar en qué consiste dicha discriminación, la segunda sala de la Suprema Corte de Justicia de la Nación comienza por el análisis de la estructura, contenido y alcances del principio contrario: el de igualdad.

En primer término, la segunda sala de la Corte precisa que, el principio de igualdad, es un derecho complejo porque se encuentra integrado por diversos artículos diseminados a lo largo y ancho de la CPEUM y tratados internacionales en materia de DDHH. En segundo lugar, la Sala esclarece que, del referido principio derivan dos normas: 1) un mandamiento de trato igual en supuestos de hechos equivalentes y 2) un mandamiento de trato desigual que constriñe al legislador a establecer distinciones entre supuestos de hecho distintos cuando así lo imponga la CPEUM. Por

${ }^{23}$ Véase, SCJN, op. cit., p. 14. 
último, la Corte mexicana precisa que el derecho humano a la igualdad posee, cuando menos, dos dimensiones: 1) una formal y 2) otra sustantiva o de hecho ${ }^{24}$.

Primero, la Sala determina que las trabajadoras domésticas reciben un trato desigual frente a supuestos de hecho equivalentes. Es decir, todos los trabajadores reciben protección social por sus servicios, menos ellas. Segundo, explica que la desigualdad de las empleadas no solo es formal sino también material. Tercero, pone en tela de juicio si esta diferenciación persigue un fin constitucional. Tras reconocer que las empleadas domésticas se encuentran en una condición de desigualdad en ambos sentidos, procede a responder la siguiente pregunta: ¿es constitucionalmente válida la exclusión de las trabajadoras domésticas del régimen obligatorio de seguridad social ante el Instituto Mexicano del Seguro Social?

El primer argumento, esgrimido por el legislador ordinario, a consideración de la segunda sala de la Suprema Corte de Justicia de la Nación, y que "justifica” (o trata de justificar) el aseguramiento potestativo de las trabajadoras domésticas al régimen obligatorio de seguridad social consiste en que, a menudo, las trabajadoras domésticas laboran para diferentes patrones y, en consecuencia, sería difícil determinar a quién corresponde la relación de trabajo. El segundo argumento es que, las labores se realizan en un hogar privado, lo que hace difícil la aplicación de la inspección del trabajo ${ }^{25}$.

Posteriormente, la segunda sala identifica una serie de afirmaciones que desbordan en cascada: 1) los ingresos de las trabajadoras domésticas son irregulares, 2) el salario en especie es frecuente, 3) en ocasiones las trabajadoras domésticas tienen su domicilio en su centro de trabajo, 4) las empleadas domésticas se encuentran en situación migratoria irregular, y 5) sus horas de trabajo son variables ${ }^{26}$.

Estos y otros argumentos, a juicio de la Corte, no son más que prejuicios que contribuyen a marginalizar a las trabajadoras domésticas pues no persiguen una distinción constitucionalmente válida. Por el contrario, laceran la dignidad humana de las empleadas domésticas al no garantizar el acceso al régimen obligatorio de seguridad social ante el Instituto Mexicano del Seguro Social porque, al no cotizar frente a dicho instituto de seguridad social, jamás se hacen acreedoras a una pensión de cesantía por edad avanzada. Más aún, en caso de accidente de trabajo, no cuentan con protección social. Esto es, no basta con percibir salarios miserables y trabajar durante jornadas inhumanas, también deben pagar sus propios gastos médicos (cuando pueden hacerlo) en caso de accidente y/o enfermedad.

De nueva cuenta, la segunda sala de la Suprema Corte de Justicia de la Nación, procede a contrario sensu. Si la diferenciación no persigue un fin constitucionalmente válido, entonces, ¿cuáles son las obligaciones del Estado mexicano en materia de seguridad social?

\section{d) Obligaciones del Estado mexicano en materia de seguridad social en favor de las trabajadoras domésticas}

En consonancia con el Pacto Internacional de Derechos Económicos Sociales y Culturales, del que el Estado mexicano forma parte y que constituye un elemento de su bloque de constitucionalidad, las autoridades mexicanas están obligadas a proporcionar seguridad social a todas las personas, sin ningún tipo de discriminación. En otras palabras, el acceso a la seguridad social no debe ser restringido de manera arbitraria o poco razonable ${ }^{27}$.

El Comité de Derechos Económicos, Sociales y Culturales de la Organización de las Naciones Unidas (ONU), añade que el Estado mexicano se encuentra obligado a prestar especial atención a las personas o grupos que, reiteradamente, han tenido dificultad para acceder al sistema de seguri-

\footnotetext{
${ }^{24}$ ibidem, p. 16.

${ }^{25}$ ibidem, p. 26 y ss.

26 idem.

${ }^{27}$ ibidem, p. 19.
} 
dad social ${ }^{28}$. Y es, precisamente, este el supuesto de las trabajadoras domésticas, como lo ha señalado en diferentes ocasiones la Organización Internacional del Trabajo (OIT), pues el empleo doméstico "ha sido tradicionalmente objeto de condiciones de trabajo inadecuadas, extensas jornadas laborales, bajos salarios, trabajo forzoso y una escasa o nula protección social; es decir, expuesto a condiciones que están lejos del concepto de trabajo decente"29.

\subsection{Aspectos negativos}

Aunque la sentencia 9/2018, dictada por la segunda sala de la Suprema Corte de Justicia de la Nación, entaña elementos positivos, tanto formales como de fondo, sus aspectos negativos son de tal magnitud que terminan destruyendo la esencia del fallo. Por decirlo de otra manera, la sentencia adquiere una dimensión tan abstracta que se convierte en una lamentable enunciación de buenos deseos hacia la impetrante y demás empleadas domésticas mexicanas. Este fallo, al no guardar una relación directa con la realidad cotidiana de un sector de la población tan marginado o desprotegido como lo son las empleadas domésticas mexicanas, termina volviéndose una clara expresión del clasismo judicial mexicano debido al desconocimiento o falta de empatía hacia las trabajadoras domésticas mexicanas y sus necesidades (criterios judiciales dictados desde una posición privilegiada). Pero lo más terrible de este supuesto fallo de "avanzada", como se verá en líneas posteriores, es la revictimización de la trabajadora impetrante. ¿Cuáles son estos defectos insoslayables? ¿Por qué ha sido evaluada esta sentencia de manera tan dura? Veamos.

\section{a) Crítica a la función "conductora" de la sentencia 9/2018}

De acuerdo con el artículo 71 de la CPEUM, una iniciativa de ley puede ser presentada por: 1) el presidente de la República Mexicana, 2) los diputados y senadores al Congreso de la Unión, 3) las legislaturas de las entidades federativas y CDMX y 4) los ciudadanos en un número equivalente, por lo menos, al $0.13 \%$ de la lista nominal de electores ${ }^{30}$. Detengámonos un momento sobre uno de los elementos esenciales de la sentencia 9/2018 de la segunda sala de la Suprema Corte de Justicia de la Nación: el "programa piloto" que debe formular el Instituto Mexicano del Seguro Social.

¿Cuál es la naturaleza jurídica de dicho "programa piloto"? ¿Es una iniciativa de ley o solo una sugerencia? Suponiendo que fuera una iniciativa de ley, ¿cuál sería el fundamento constitucional para que el Instituto Mexicano del Seguro Social pudiera presentar un "programa piloto" ante el Congreso de la Unión? En el supuesto de que la ley reglamentaria del Instituto Mexicano del Seguro Social facultara a este organismo del Estado para presentar "programas piloto" o una iniciativa de ley, dicha disposición sería claramente inconstitucional porque no encuadra en ninguno de los supuestos del artículo 71 de la Constitución.

Si el "programa piloto" que prescribe la sentencia 9/2018 de la segunda sala de la Suprema Corte de Justicia de la Nación fuera una sugerencia, el Instituto Mexicano del Seguro Social cumpliría su obligación al presentar dicho documento ante el Congreso de la Unión. ¿Esto garantizaría que en un plazo no mayor a 3 años, "se logre obtener la seguridad social, efectiva, robusta y suficiente de la totalidad de las empleadas domésticas en el país?"

\footnotetext{
${ }^{28}$ ibidem, p. 20.

${ }^{29}$ ibidem, p. 23.

${ }^{30} \mathrm{El}$ texto de la CPEUM se encuentra disponible en: http://www.diputados.gob.mx/LeyesBiblio/ref/cpeum.htm
} 
Además, ¿ante qué persona del Congreso de la Unión debe ser presentado el "programa"? ¿Ante una comisión permanente? ¿Cuál? ¿Ante un diputado o senador? ¿De qué bancada? Ellos tan solo tendrían que recibir el documento y nada más. Por si fuera poco, esa "iniciativa" o "programa piloto" podría ser aplazado indefinidamente por no formar parte de la "agenda política" del propio Congreso de la Unión o cualquiera de las fracciones parlamentarias.

Esta prescripción de la sentencia 9/2018, este "programa piloto", no es otra cosa más que una idea que carece de sustento constitucional ni legal. Lo que es más, ni siquiera es una norma porque no está enlazada a ninguna sanción, a lo mucho es un buen deseo. Si bien es cierto la ley deja de ocupar un papel central, en tanto fuente del derecho, en el Estado de Derecho Constitucional $^{31}$, esto no se traduce, de ninguna manera, en el abandono de la certeza que confiere la norma positiva $^{32}$. Todos los actos del Estado, máxime las sentencias de una corte constitucional, deben ser dictadas de acuerdo a lo que prescriba la Constitución y la ley ${ }^{33}$. ¡Vaya paradoja, que una sentencia constitucional carezca de sustento constitucional y legal!

\section{b) Falacia naturalista}

Esta falacia en el razonamiento jurídico ha sido enunciado, doctrinariamente, de la siguiente forma: "que algo sea no significa que deba ser, que algo deba ser no significa que sea". En el sumario de la sentencia 9/2018 se lee el siguiente, y desafortunado, "razonamiento": "[...] la finalidad de los anteriores lineamientos consiste en que, [...] en un plazo no mayor a 3 años, se logre obtener la seguridad social, efectiva, robusta y suficiente a la totalidad de las empleadas domésticas en el pais" "34. ¿Puede una norma o una sentencia cambiar la realidad de una sociedad a tal punto que exista una coincidencia total entre el ser y el deber ser? La respuesta es absolutamente negativa.

Hans Kelsen, con gran precisión, en su Reine Rechtslehre $e^{35}$, demostró que las ciencias sociales en general y, el derecho en particular, se rigen por el principio de imputación. Es decir, si $A$ debe ser $B$. Por su parte, las ciencias naturales están sujetas al principio de causalidad; si $A$ tiene que ser B. En otras palabras, las ciencias naturales describen fenómenos regidos por el principio de causaconsecuencia. Una norma jurídica dejaría de ser derecho si el supuesto expresado en ella siempre coincidiera con la situación de hecho que regula, porque desaparecería, entre $A$ y $B$, un vínculo de deber ser para convertirse en una relación de $\operatorname{ser}^{36}$.

Eduardo García Máynez, sobre esta distinción kelseniana, explica: “[s]i la eficacia de una norma pudiera llegar al límite superior de cumplimiento indefectible o, si no pudiera dejar de ser obedecida, en ese mismo instante dejaría de ser regla de conducta, para transformarse en ley de la naturaleza" ${ }^{37}$. De ahí la imposibilidad para garantizar, en todo momento, "seguridad social, efectiva, robusta y suficiente a la totalidad de las empleadas domésticas en el país”.

\footnotetext{
${ }^{31}$ Véase, ZAGREBELSKY, Gustavo, El derecho dúctil. Ley, derechos, justicia, 10a ed., Madrid, Trotta, 2011, pp. 21-46.

${ }^{32}$ Véase, GUASTINI, Riccardo, Gerarchie normative, Revus. Journal for Constitutional Theory and Philosophy of Law, 21, 2013, p. 21 y ss.

${ }_{33}$ cfr., GARCIA AMADO, Juan Antonio, Nazismo, Derecho y Filosofía del Derecho, Anuario de Filosofía del Derecho, VIII, 1991, p. 346 y ss.

${ }^{34}$ Véase, infra, parágrafo 2.2 de este documento. Énfasis añadido.

${ }^{35}$ Véase, KELSEN, Hans, Reine Rechtslehre. Einleitung in die rechtswissenschaftliche Problematik, Tubinga, Mohr Siebeck, 2008, pp. 15-50; la distinción entre el principio de imputación y causalidad es matizada en la segunda edición de su opus magnum, véase, KELSEN, Hans, Teoría Pura del Derecho, 16a ed., México, Porrúa, trad. de VERNENGO, Roberto J., 2009, pp. 15-70.

${ }^{36}$ Véase, GARCÍA MÁYNEZ, Eduardo, Algunos aspectos de la doctrina kelseniana. Exposición crítica, México, ediciones Coyoacán, 2011, p. 16 y ss; véase también, KELSEN, Hans, Derecho y lógica, 2a ed., México, ediciones Coyoacán, trad. de SCHMILL ORDONEEZ, Ulises Schmill y CASTRO VALLE, Jorge, 2016, p. 14 y ss.

${ }^{37}$ ibidem, p. 16.
} 
La afirmación anterior significa que todos los patrones, siempre, a partir del dictado de la sentencia 9/2018, inscribirían a sus trabajadoras domésticas en el régimen obligatorio del IMSS. ¿Realmente eso sucedería? ¿Cómo estar seguros? ¿De qué manera se vigilaría el cumplimiento de esta orden? ¿Puede el Estado mexicano supervisar el acatamiento estricto de este mandato? De nueva cuenta la respuesta es negativa, no faltaría el patrón que, por maldad, indiferencia o simple desconocimiento de la norma, no cumpliera con este precepto. En efecto, algunos evitarán inscribir a sus trabajadoras domésticas para eludir las cargas fiscales y pago de las cuotas obrero-patronales ante el Instituto Mexicano del Seguro Social. Otros, por su parte, debido a su falta de empatía (no necesariamente persiguiendo un lucro), torpeza o pereza no inscribirán a sus empleadas domésticas ante el instituto mencionado.

Por último, no debe perderse de vista que los patrones mexicanos, no tienen dentro de sus prioridades revisar todas las mañanas el Diario Oficial de la Federación (DOF) o Semanario Judicial de la Federación (SJF) para enterarse de los cambios legislativos y criterios jurisprudenciales más novedosos. Es decir, seguramente muchos patrones de México están tan conscientes sobre la existencia de esta sentencia de la Corte, como los abogados nacionales están al tanto de los indicadores con los que concluyó su actividad, el día de ayer, la Bolsa Mexicana de Valores (BMV) o Wall Street.

La afirmación garantizar "seguridad social, efectiva, robusta y suficiente a la totalidad de las empleadas domésticas en el país", es tan cierta y racional como querer cambiar el eje, sentido de rotación de la Tierra o posición del planeta en el universo, a través de una sentencia de la SCJN, decreto presidencial o ley del Congreso de la Unión.

\section{c) Contravención al principio de relatividad de las sentencias del juicio de amparo mexicano.}

La fisonomía del juicio de amparo mexicano, no obstante su evolución a través del tiempo, está condicionada por ciertos principios; entre los que destaca el de relatividad de las sentencias. ¿Qué quiere decir esto? Que los efectos de los fallos de una sentencia de amparo no tendrán efectos erga omnes, pues solo afectan a las partes involucradas en el conflicto ${ }^{38}$. Esto es, una sentencia de amparo no podría declarar inconstitucional, con efectos generales, una norma. En ese sentido, Edmundo Elías Mussi y Luciano Silva Ramírez explican:

El principio de relatividad de las sentencias, también conocido como Fórmula Otero, [...] consiste en los alcances particulares de las sentencias de amparo. Éste ha sido motivo de polémica hasta nuestros días, sobre todo en el amparo contra leyes, ya que debido a dicho principio, el efecto de las sentencia (sic) que otorga el amparo al quejoso, declarando inconstitucional una ley, no significa que la norma se derogue, salga del mundo jurídico, sólo se dejará de aplicar al gobernado que la impugnó y obtuvo el amparo; la ley tildada de inconstitucional sigue conservado su vigencia y fuerza material, por lo tanto se seguirá aplicando al grueso de la población, a los destinatarios de la norma, que no la combatieron, o que si lo hicieron, el juicio de garantías les fue sobreseído o negado ${ }^{39}$.

Sin embargo, sí existe una vía para expulsar, con efectos generales, una norma del ordenamiento jurídico mexicano: la acción de inconstitucionalidad. Desde luego, este documento no pretende ser una exposición exhaustiva, erudita, de derecho procesal constitucional mexicano. Por tanto, es suficiente mencionar, que la acción de inconstitucionalidad es el mecanismo jurisdiccional

${ }^{38}$ Véase, CAMPUZANO GALLEGOS, Adriana, Manual para entender el Juicio de Amparo, $3^{\mathrm{a}}$ ed., México, Thomson Reuters, 2017, pp. 135-137; cfr., BURGOA ORIHUELA, Ignacio, El Juicio de Amparo, 20ª ed., México, Porrúa, 1983, p. 532.

${ }^{39}$ ELÍAS MUSSI, Edmundo \& SILVA RAMÍREZ, Luciano, La Fórmula Otero y la declaratoria general de inconstitucionalidad en el Juicio de Amparo contra normas, en GONZÁLEZ OROPEZA, Manuel \& FERRER MAC-GREGOR, Eduardo, El Juicio de Amparo. A 160 años de la primera sentencia, México, UNAM-IIJ, tomo I, 2009, p. 27. El texto se encuentra disponible en: https:// archivos.juridicas.unam.mx/www/bjv/libros/7/3066/4.pdf 
por medio del cual, algunos órganos del Estado mexicano que se encuentran legitimados para ello, pueden denunciar la incongruencia de una norma con el bloque de constitucionalidad, para que ésta sea expulsada del ordenamiento jurídico con efectos generales ${ }^{40}$.

Si la sentencia 9/2018 de la segunda sala de la Suprema Corte de Justicia de la Nación no deriva de una acción de inconstitucionalidad sino de un juicio de amparo directo, esto es, si sus efectos no son erga omnes de acuerdo con la Fórmula Otero ¿de qué manera se supone que la declaratoria de inconstitucionalidad, expresada en este fallo, respecto a la facultad potestativa de los patrones para inscribir en el régimen obligatorio del IMSS a las trabajadoras domésticas, surtirá efectos generales?

En otras palabras, ¿esta resolución realmente podrá garantizar el acceso efectivo a la seguridad social de todas las empleadas domésticas mexicanas como se enuncia en su sumario? Tal parece que no; en consecuencia, dicha afirmación no es más que un recurso emotivo, estridente, llamativo o pretencioso de la sentencia 9/2018.

\section{d) Revictimización de la empleada doméstica impetrante}

A pesar de todos los razonamientos anteriores, el aspecto más grave de esta sentencia, el punto que mayor vergüenza causa, el elemento más infame y deleznable de este fallo, es la revictimización de la impetrante. Sin duda alguna, la trabajadora doméstica (Quejosa) es una víctima, tanto de sus patronas como del propio Estado mexicano.

Víctima en tanto que sus patronas, desde el 11 de enero de 1959, evitaron inscribirla en el sistema de seguridad social mexicano. En otras palabras, la "trabajadora" doméstica estuvo reducida a un estado de semi-esclavitud, debido a su pobreza, ignorancia y género. Durante mucho tiempo estuvo sin seguridad social: 57 años (desde 1959 hasta 2016). ¡Qué hecho tan vergonzoso para las instituciones y población mexicana!jNormalización de la semi-esclavitud!

Víctima en tanto que el Estado mexicano no hizo justicia en este fallo. Por una parte, y como se ha visto en líneas superiores, la segunda sala de la Suprema Corte de Justicia de la Nación desprecia el propio andamiaje constitucional y legal, cuando y como quiere ("programas piloto" y demás directrices sin sustento constitucional o legal), desprecia el andamiaje jurídico mexicano para aparentar ser un tribunal constitucional de avanzada a la altura de la Corte Constitucional de Colombia o Tribunal Constitucional de Espańa. Lo que importa es la forma, la apariencia sobre el fondo, aparentar es ser.

La sentencia 9/2018 absuelve a las codemandadas, así como al Estado mexicano, a la inscripción retroactiva ante el Instituto Mexicano del Seguro Social e Instituto del Fondo Nacional de la Vivienda para los Trabajadores porque, cuando surgió la relación de trabajo y mientras existió, el derecho vigente no hacía obligatoria la inscripción de las trabajadoras domésticas al régimen obligatorio ante el Instituto Mexicano del Seguro Social. De acuerdo con el "razonamiento" (?) de la segunda sala de la Corte, fallar de otro modo sería faltar al principio de seguridad jurídica en favor de los gobernados. ¿Cómo? ¿Por una parte desprecia las disposiciones constitucionales y legales al indicar ciertas "directrices" ("programa piloto") a las instituciones jurídicas nacionales pero, por la otra, respeta en sentido "estricto" la legalidad?

El fallo puede ser expresado en otros términos: "a pesar de haber trabajado durante 57 años al margen de la ley, a pesar de haber sido reducida durante 57 años a una condición de semiesclavitud, a pesar de haber invertido tiempo, dinero y esfuerzo en dos juicios (el natural y el juicio de amparo), a pesar de acudir a este tribunal reclamando aquello que por derecho te pertenece: Justicia, lamentamos informarte que no maximizaremos tu derecho humano a la seguridad social y

${ }^{40}$ Véase, BARRERA GARZA, Óscar, Compendio de amparo, 2a ed., México, Porrúa, 2017, p. 54. 
vivienda, no tienes derecho a ninguna pensión por edad avanzada, no tienes derecho a una vivienda digna, pero no te preocupes, toma, aquí está tu carta de buenos deseos, gracias y mejor suerte para la próxima". Estos son algunos extractos en donde se "dirime" la controversia:

[...] ésta Corte Constitucional considera que no resulta posible condenar, ni a la parte patronal, ni al Instituto Mexicano del Seguro Social, al pago retroactivo de las cuotas de seguridad social respectivas, ni otras prestaciones que se encuentran previstas en el régimen obligatorio de tal Instituto.

Lo anterior, ya que resulta inconcuso que la norma impugnada, al establecer que las trabajadoras domésticas pertenecen al régimen voluntario -y, por ende, que no existía obligación alguna del patrón de inscribirlas ante el Instituto Mexicano del Seguro Social-, gozaba de la plena presunción de constitucionalidad y, por ende, previo a la interposición del presente juicio de amparo, no existía obligación jurídica alguna que pudiese serle reclamada al patrón respecto a la "omisión" de inscribir a la quejosa ante el Instituto Mexicano del Seguro Social y a la de pagar las cuotas de seguridad social respectivas, ni tampoco débito alguno que pudiese serle legalmente reprochable a ese Instituto.

En efecto, la aceptación del Estado de Derecho, como un principio constitucional, requiere que un ciudadano, antes de comprometerse con una determinada línea de acción, sepa por adelantado cuáles son los principios y obligaciones legales que derivan de ésta.

[...]

En ese sentido, condenar retroactivamente a la parte patronal o al Instituto Mexicano del Seguro Social, a que enteren las cuotas concernientes de seguridad social o que se otorguen ciertas prestaciones sociales, implicaría una clara violación al principio de legalidad y seguridad jurídica, al pretender dotar de efectividad en el pasado una obligación que, conforme a las normas vigentes y bajo la presunción de constitucionalidad de las leyes, no era exigible para sujeto de derecho alguno.

Sin embargo, lo anteriormente expuesto no implica que el vicio de inconstitucionalidad detectado no depare ningún efecto práctico. [...] esta Corte Constitucional [...] se encuentra obligado (sic) a emitir directrices que orienten a las autoridades estatales competentes, respecto a la necesidad y el deber que tienen de cumplimentar, de manera efectiva, con la protección y goce del derecho humano a la seguridad social de las trabajadoras domésticas ${ }^{41}$.

La sentencia 9/2018 es un desastre pues confunde los efectos que tiene la norma, por una parte, hacia los gobernados y, por la otra, hacia las autoridades, también es incapaz de distinguir entre la obligación estatal de reparación del daño y la garantía de no repetición. En efecto, es correcto, cuando menos jurídicamente, que la segunda sala de la Suprema Corte de Justicia de la Nación absolviese a las codemandadas del pago de las cuotas al Instituto Mexicano del Seguro Social porque sería darle un efecto retroactivo negativo a una norma individualizada (sentencia) en su perjuicio. Cabe destacar, al respecto, que la Constitución mexicana prohíbe terminantemente esta clase de operaciones en los artículos 14 y 16.

Sin embargo, los efectos de la norma hacia las autoridades estatales son totalmente diferentes. En el Estado de Derecho Constitucional, el Estado es una suerte de dique entre el gobernado ${ }^{42}$ y cualquier poder salvaje ${ }^{43}$. En el Estado de Derecho Constitucional la responsabilidad del Estado es única e indivisible, trasciende a través del tiempo. De esta forma, una arbitrariedad estatal puede ser cometida en cierta época y no ser sancionada de manera inmediata por diferentes causas (complicidad de políticos y autoridades, corrupción, dictaduras, etcétera); sin embargo, mutadas las condiciones, el Estado debe reparar, de diferentes maneras, todas aquellas violaciones en materia de DDHH. Actuar

\footnotetext{
${ }^{41}$ SCJN, 9/2018, pp. 50-51. Énfasis ańadido.

${ }^{42}$ Cfr. UPRIMNY, Rodrigo, Estado de Derecho, Eunomía. Revista en Cultura de la Legalidad, no. 5, 2013, pp. 168-175.

${ }^{43}$ Cfr. FERRAJOLI, Luigi, Manifiesto por la igualdad, Madrid, Trotta, trad. de IBANEZ, Perfecto Andrés, 2019, pp. 13-40, 109-128.
} 
de manera contraria significaría solapar leyes injustas solo porque eran derecho vigente, conduciría a justificar cualquier clase de injusticia extrema. Sin embargo, es un principio ampliamente reconocido que en el Estado de Derecho Constitucional la injusticia extrema no es derecho ${ }^{44}$.

En la especie, si bien es cierto el ordenamiento jurídico no contemplaba a las trabajadoras domésticas dentro del régimen obligatorio ante el Instituto Mexicano del Seguro Social, esta diferenciación jamás persiguió un fin constitucionalmente válido. Más aún, dicha excepción estuvo sostenida en prejuicios de género por medio de los cuales el trabajo doméstico era, y es, considerado una actividad inferior, indigna. De ahí que, al no condenar al Instituto Mexicano del Seguro Social, en tanto órgano constitutivo del Estado, al otorgamiento, en favor de la Quejosa, de una pensión por cesantía y edad avanzada, esta sentencia de la segunda sala de la Suprema Corte de Justicia de la Nación, en realidad, entrańa un perverso efecto revictimizante.

Efectivamente, la trabajadora doméstica, durante 57 ańos estuvo privada de seguridad social por su condición económica, ignorancia y género, por si fuera poco, tuvo que soportar la carga económica y psicológica de dos juicios (natural y juicio de amparo) para no recibir la garantía, la certidumbre, de una pensión por cesantía y edad avanzada que le permitiera gozar de cierta estabilidad económica durante las postrimerías de su existencia.

En ese sentido, resulta totalmente paradójico, surrealista y absurdo que, por una parte, la segunda sala de la Suprema Corte de Justicia de la Nación busque asegurar la protección de "todas" las trabajadoras de México pero, por la otra, no pueda maximizar el derecho humano a la seguridad social y vivienda digna de la impetrante, de una sola persona. Es decir, con su sentencia "protegió" a todas las trabajadoras domésticas y, a la vez, a nadie.

El temor de la segunda sala a distorsionar el presupuesto del Estado mexicano no se encuentra justificado porque su sentencia no tiene efectos generales, sino particulares. Es decir, mediante su fallo no está constriñendo al Estado mexicano al pago de millones de pesos en favor de todas las trabajadoras domésticas porque una sentencia de amparo no tiene efectos generales. Además, vista la situación desde una perspectiva estrictamente utilitaria, una pensión en favor de la trabajadora no significaba una erogación estratosférica para el Estado mexicano si se considera la esperanza de vida de mujeres y hombres en el país.

Si algo pudiera rescatarse de este lamentable fallo sería la intención, por parte de la segunda sala de la Corte, de crear una suerte de garantía de no repetición al tratar de constreñir en lo futuro, mediante sus directrices, tanto a los patrones como a las autoridades de seguridad social, a inscribir obligatoriamente a todas las trabajadoras domésticas. Empero, estas directrices expresadas en el cuerpo de su sentencia, así como su "programa piloto", debido a su ineficacia, terminan convirtiéndose en una broma de mal gusto para las trabajadoras domésticas de México. Por si fuera poco, a diferencia de la Corte Constitucional de Colombia, la Corte mexicana no da seguimiento a sus propios fallos.

\section{Consideraciones finales}

Recientemente, los artículos 338 a 340 de la Ley Federal del Trabajo fueron derogados; estos artículos excluían del régimen obligatorio de seguridad social a las trabajadoras domésticas mexicanas. Para no faltar a la verdad, cabe precisar que esta derogación fue, hasta cierto punto, un eco de la sentencia 9/2018 de la segunda sala de la Suprema Corte de Justicia de la Nación. En efecto, fue tan

${ }^{44}$ Véase, RADBRUCH, Gustav, "Five Minutes of Legal Philosophy (1945)", Oxford Journal of Legal Studies, vol. 26, no. 1, 2006, pp. 13-15. 
solo un eco, porque el fallo no vinculaba estrictamente ni al Congreso de la Unión ni al Instituto Mexicano del Seguro Social. Estos artículos fueron derogados, más bien como una deuda política, como una estratagema para mantener una posición en las encuestas en un contexto electoral, más que como un acto auténtico por mejorar las condiciones de las trabajadoras de México.

Hace casi dos años que feneció el plazo indicado por la Corte mexicana; hasta la fecha no existe programa piloto alguno en favor de las empleadas domésticas mexicanas ni se ha sancionado al referido instituto por su "incumplimiento". Más aún, ya transcurrieron los tres años indicados en las sentencia para que todas las trabajadoras gozaran de seguridad social. Sin embargo, la mayoría de ellas aún carecen de seguridad social.

La sentencia 9/2018 de la segunda sala de la Suprema Corte de Justicia de la Nación es irrespetuosa con las trabajadoras domésticas mexicanas en general, así como la impetrante en particular porque, más allá de la apariencia, no se tutelan de manera efectiva sus derechos sociales. Esta sentencia hace a un lado un cúmulo amplio de preceptos constitucionales y legales con el propósito de dar la apariencia de ser un fallo innovador, de avanzada, a la vanguardia de lo que hacen otros tribunales constitucionales de Iberoamérica como la Corte Constitucional de Colombia o el Tribunal Constitucional de España.

Podría decirse que, en cierta medida, constituye una muestra de irresponsabilidad institucional y falta de compromiso, tanto moral como real, de los juzgadores federales porque se encuentra desconectada de las condiciones y necesidades reales de la población mexicana. La sentencia podría ser considerada como una falta de empatía hacia uno de los sectores mas vulnerables de la población, las empleadas domésticas, porque ellas no viven de buenas intenciones, así como los ministros y secretarios de la Suprema Corte de "Justicia" de la Nación no desempeñan sus cargos de manera honorífica.

\section{Fuentes de consulta}

ALEXY, Robert, Teoría de la argumentación jurídica. La teoría del discurso racional como teoría de la fundamentación jurídica, 2a ed., Madrid, Centro de Estudios Políticos y Constitucionales, trad. de ATIENZA, Manuel y ESPEJO, Isabel, 2014.

ATIENZA, Manuel, Curso de argumentación jurídica, Madrid, Trotta, 2013.

- Las razones del derecho. Teorías de la argumentación jurídica, México, UNAM-IIJ, 2005.

— "El derecho como argumentación", Isegoría, No. 21, 1999.

BARRERA GARZA, Óscar, Compendio de amparo, 2ª ed., México, Porrúa, 2017.

BURGOA ORIHUELA, Ignacio, El Juicio de Amparo, 20a ed., México, Porrúa, 1983.

CARRILlO SALGADO, Augusto Fernando, Panorama de la protección de los derechos de las trabajadoras en España y México, Labos. Revista de Derecho del Trabajo y Protección Social, Vol. 1, No. 3, 2020.

CAMPUZANO GALLEGOS, Adriana, Manual para entender el Juicio de Amparo, $3^{\mathrm{a}}$ ed., México, Thomson Reuters, 2017.

CRUZ PARCERO, Juan Antonio, Hacia una teoría constitucional de los derechos humanos, México, Instituto de Estudios Constitucionales del Estado de Querétaro, 2017.

FERRAJOLI, Luigi, Manifiesto por la igualdad, Madrid, Trotta, trad. de IBAÑEZ, Perfecto Andrés, 2019.

GONZÁLEZ OROPEZA, Manuel \& FERRER MAC-GREGOR, Eduardo, El Juicio de Amparo. A 160 años de la primera sentencia, México, UNAM-IIJ, tomo I, 2009.

GARCIA AMADO, Juan Antonio, Nazismo, Derecho y Filosofía del Derecho, Anuario de Filosofía del Derecho, VIII, 1991. 
Augusto Fernando Carrillo Salgado ¿Justicia social o revictimización de la trabajadora doméstica mexicana?...

GARCÍA MÁYNEZ, Eduardo, Algunos aspectos de la doctrina kelseniana. Exposición crítica, México, ediciones Coyoacán, 2011.

GUASTINI, Riccardo, Gerarchie normative, Revus. Journal for Constitutional Theory and Philosophy of Law, 21, 2013.

KELSEN, Hans, Reine Rechtslehre. Einleitung in die rechtswissenschaftliche Problematik, Tubinga, Mohr Siebeck, 2008

- Teoría Pura del Derecho, 16a ed., México, Porrúa, traducción de Roberto J. Vernengo, 2009. - Derecho y lógica, 2a ed., México, ediciones Coyoacán, trad. de SCHMILL ORDONEZZ, Ulises Schmill Ordoñez y CASTRO VALLE, Jorge, 2016.

RADBRUCH, Gustav, Five Minutes of Legal Philosophy (1945), Oxford Journal of Legal Studies, vol. 26, no. 1, 2006.

UPRIMNY, Rodrigo, Estado de Derecho, Eunomía. Revista en Cultura de la Legalidad, no 5, 2013. ZAGREBELSKY, Gustavo, El derecho dúctil. Ley, derechos, justicia, 10a ed., Madrid, Trotta, 2011. CPEUM

S.A., Nueva Ley Federal del Trabajo, México, Gallardo Ediciones, 2020.

SCJN 8/2018.

SCJN 9/2018.

SCJN 1464/2013 